source of error is likely to be crucial in determining whether the adaptive system will work. It puts a large dent in any hopes of using existing equipment and facilities with adaptive optics.

The training of most observational astronomers leaves them unprepared for the immense technical skills in design and construction that are required to get to grips with adaptive optics. Early astronomers had to design and build their own equipment because they understood the problems and solutions better than did industry, and could not afford industrial prices. But this certainly gave them an advantage. Similarly, if young astronomers are to take advantage of adaptive optics, their training must change.

Unfortunately, the book will not be very helpful to the trainee astronomer. For example, many have realized that the use of 2-micrometre infrared light is the easy way to become acquainted with adaptive optics, but infrared is not even mentioned in the index. The intended audience of the book is too broad, and too much emphasis is placed on theory rather than practice. And the omission of aspects of speckle will leave the reader without an important tool to understand various options and critical limits of adaptive systems. These are important: for example, when a corrected telescope is between a factor of three and six times too large to be limited by diffraction, the simplest adaptive system changes from being one that does not work to one that is very useful. Nor are the options for guiding on the brightest speckle discussed.

There is a faith in the astronomical community that laser beacons will solve all problems, and that the largest telescopes will soon be operating up to the visible diffraction limit. This is very optimistic. What about the self-spoiling aspects of current telescopes? And should we not consider the time it takes to develop even simple devices, let alone adaptive optics? Finally, laser systems have their limitations in both performance and price. Laser-corrected images will whiz around unless there is a second servoloop to correct this by stabilizing the position of a star image, and these stars will always be faint. Laser beams directed at the atmosphere do not sample the same region of air as the parallel beam from a star, and the problem gets worse as the aperture gets larger. The solution might be to use many different laser beams or starlight, but these add one more layer of complexity. The promise is there, but there will be several more books before the systems are.

Neville J. Woolf is at the Steward Observatory, University of Arizona, Tucson, Arizona 85721, USA.

\section{Man out of time}

\section{Alasdair Whittle}

Archaeology: Theories, Methods and Practice. By Colin Renfrew and Paul Bahn. Thames and Hudson: 1991. Pp.543. £18.95, \$29.95.

ARCHAEOLOGY is itself now of some antiquity. It was properly established between 1840 and 1870, when it acquired a timescale and explanations with which to interpret our long past. Since then it has accumulated an astonishing list of achievements. The record of human existence has been pushed back to more than three million years ago. The social and technological success of Palaeolithic people has been charted across the globe. The 'Neolithic revolution', the early postglacial emergence of sedentary lifestyles and food production, has been traced not only in western Asia, but also in eastern Asia, China and the United States. Evidence has also been found around the world of early civilizations, many of them urban, socially complex, literate and technologically advanced, a foretaste of (forewarning to?) the modern world. And the purely archaeological story merges with the ancient and mediaeval worlds known from historical sources. Archaeologists now have lively debates about the nature of historical change, about the evolution of social formations, and about the experience and meaning of being human.

The subject has not lacked for wider appeal beyond its practitioners. Archaeology was already popular in the nineteenth century and has lost none of its intrinsic fascination for many ordinary people. Some sites in England, such as Stonehenge and Avebury, victims of their own appeal, are at risk from too many visitors. And in many Western countries, archaeology has become more or less embedded in the planning process, recognized as an important factor in the modern landscape.

For all this success and popularity, there is still a lot of ignorance about what archaeologists think and do. Many would-be students are attracted by the exotic and glamorous (the Indiana Jones syndrome), and many parents and teachers are still suspicious of the intellectual credentials of the discipline. Even academics have their doubts, from arrogant modern-historians surfeited with information, to scientists mistrustful of what they see as a lack of procedural rigour. And this ignorance can extend to all manner of owners and occupiers of land, as well as to officials, politicians and so on.

Archaeology is doubly satisfying as an introduction to the subject. On the one hand, it celebrates the achievements of the discipline and revels in the worldwide scope of enquiry and in the vast human timescale. On the other, it takes the reader gently but thoroughly through a veritable encyclopaedia of information about procedures, techniques, explanations and results, enough surely to convince even the most sceptical of the challenge and value of archaeology. That information is well presented by the now-familiar technique of inserts, boxes and special features alongside the regular text, and is intelligently organized around a series of simple questions about people in the past: what did they eat? what did they think? and so on. To its credit, the book does not seek to provide a series of simple answers, although it is always ready to give some idea of what an answer might look like. This should be particularly valuable to university students who are starting the difficult process of thinking about the nature of problems, and who are asked to abandon their desire for certainty.

The book is not only an introduction but also a contribution to the debate about how archaeology should be conducted. In wider terms, it is modernist rather than postmodernist; in archaeology's own unlovely jargon, processual rather than postprocessual. The authors believe in an ultimately knowable past, provided that appropriate procedure, relevant questions and the luck of discovery all coincide. They are not concerned about the relativist interpretation of pasts invented in the present to serve the purposes of the modern world. The authors' position is vigorously argued as a subtext throughout the book, but the opposing view is also given a fair airing. Other modern issues are also discussed, including the disturbance of the dead and the return of cultural materials to the countries of their origin.

It may seem parochial to complain that there is not more on the Mediterranean and Europe, and on the classical and early mediaeval worlds. These are important in many UK university degree courses. The book seems to be aimed at a US market, but the wider geographical scope would be unlikely to do any student much harm.

There have been many distinguished and successful introductions to archaeology. This is, quite simply, by far the best available.

Alasdair Whittle is in the School of History and Archaeology, University of Wales College of Cardiff, Cardiff CF1 3XU, UK.

\section{Autumn Books}

Great Mambo Chicken and the Transhuman Condition, Junk Science and Fantastic Archaeology are just three of the books to be featured in the Autumn Books supplement in next week's Nature. 